CAVALHEIRO \& NISHIJIMA, v(5), n5, p. 658 - 669, 2012.

Revista Eletrônica em Gestão, Educação e Tecnologia Ambiental

REGET/UFSM (e-ISSN: 2236-1170)

\title{
UMA REVISÃO BIBLIOGRÁFICA REFLEXIVA SOBRE A ABORDAGEM DOS RIACHOS DEGRADADOS NA ESCOLA SOB A PERSPECTIVA DAS SITUAÇÕES DE ESTUDO NA EDUCAÇÃO AMBIENTAL ${ }^{1}$
}

\author{
Laísa Wociechoski Cavalheiro, Toshio Nishijima \\ ${ }^{1} \mathrm{O}$ presente artigo apresenta um recorte da monografia apresentada ao Curso de Especialização em Educação \\ Ambiental da Universidade Federal de Santa Maria (UFSM, RS) em julho de 2011.
}

\section{RESUMO}

A problemática dos riachos degradados trata-se de uma questão de cidadania que deve permear a vivência escolar. A abordagem destas questões sob as perspectivas da Educação Ambiental é um meio de sensibilizar os sujeitos a desenvolver uma postura consciente de preservação dos recursos hídricos. O objetivo geral deste artigo consiste em analisar sob a ótica da Educação Ambiental na escola a problemática dos riachos degradados. São objetivos específicos: relacionar a proposta metodológica das Situações de Estudo à Educação Ambiental; refletir sobre a preservação dos riachos na perspectiva da Educação Ambiental na escola. A técnica metodológica empregada nesta pesquisa consiste em uma revisão bibliográfica com intuito de obter informações sistematizadas, sintetizadas e reelaboradas a partir de reflexões críticas dos autores e construir (ou reconstruir) ideias criando um arcabouço teórico capaz de sustentar ou subsidiar abordagens dos riachos degradados nas escolas sob o enfoque da Educação Ambiental e a estratégia de ensino das Situações de Estudo. A Educação Ambiental na escola é um veículo dialógico para os estudantes conscientizarem-se, por suas vivências individuais e coletivas, da importância de preservação dos cursos d'água e da adoção de medidas mitigatórias aos impactos antrópicos negativos dos riachos brasileiros, enquanto as Situações de Estudo são uma metodologia adequada à sensibilização dos sujeitos porque trabalham com conhecimentos específicos aliados às questões sociais, contextualizando assim as propostas de ensino à realidade de cada escola.

Palavras-chave: Riachos degradados, Educação Ambiental, Situações de Estudo.

\section{ABSTRACT}

The problem about degraded streams is a matter of citizenship that must pervade the school life. The approach on these questions in the perspective of Environmental Education is a way to move individuals in order to develop awareness to preserve water sources. The general objective of this work consists in analyzing, under the view of the Environmental Education in the school, the problem about degraded streams. The specific objectives are: to relate the methodological proposal of the Study Situations to the Environmental Education and; reflect about the preservation of the streams in the perspective of the Environmental Education in the school. The methodological approach used in this research consists of a bibliographic review in order to gather information, which is systematized, synthesized and reorganized after critical reflection of the authors, and construct (or reconstruct) ideas by creating a theoretical frame which is able to support or subsidize approaches, in the school, on degraded streams, in the perspective of the Environmental Education and the strategy of the Study Situations. The Environmental Education in 
CAVALHEIRO \& NISHIJIMA, v(5), n5, p. 658 - 669, 2012.

\section{Revista Eletrônica em Gestão, Educação e Tecnologia Ambiental}

REGET/UFSM (e-ISSN: 2236-1170)

the school is a dialogical way for the students to become aware, by means of their individual and collective experiences, of the importance of the preservation of water sources and the adoption of measures for mitigation of the negative anthropic impact on Brazilian streams, while the Study Situations are an adequate methodology to the sensitization of the individuals because these situations work with specific knowledge allied to social matters, contextualizing in this way the teaching proposals to the reality of each single school.

Key words: Degraded streams, study situation, Environmental Education.

\section{INTRODUÇÃO}

Os riachos são ambientes suscetíveis a impactos antrópicos negativos e são definidos como rios de pequena ordem, com possíveis áreas de inundação em períodos chuvosos e gradientes de poções, remansos e corredeiras com rochas e pedras (ESTEVES; ARANHA, 1999). A ocupação humana desordenada e a deficiência de fiscalização nas construções civis implicam na derrubada de matas ciliares e na instalação de habitações nas margens de córregos e riachos, ocasionando prejuízo ambiental e risco a própria população (SANTOS; REIS, 1997).

Os desmatamentos alteram os habitats das bacias hidrográficas e a dinâmica trófica destes ecossistemas, implicando na diversidade e composição das espécies (FELIPE; SÚAREZ, 2010). A manutenção das matas ciliares contribui com o fluxo gênico entre as espécies enquanto corredor ecológico para o deslocamento da fauna, com a proteção contra processos erosivos do solo em regiões topográficas acidentadas e com a qualidade da água dos rios, riachos e córregos quando funciona como filtro para poluentes e sedimentos (TERRES; MÜLLER, 2008).

A remoção das matas ciliares e o lançamento de efluentes na água estão entre as ações que mais comprometem a integridade biótica dos riachos, sendo que as dimensões reduzidas destes ecossistemas, quando comparados com rios de grande porte, tornam os riachos mais sensíveis às alterações antrópicas (OLIVEIRA; BENNEMANN, 2005).

Obras de saneamento inadequadas ou a inexistência dos sistemas de tratamento de efluentes nos centros urbanos proporciona à população a adoção das mais diversas soluções para o escoamento do esgoto doméstico, como a construção de fossas negras, sépticas e sumidouros, ou mesmo o lançamento "in natura" em valas, galerias pluviais e canais de drenagem (SANTOS; REIS, 1997). Estas soluções poluem, além dos cursos d'água, o solo, o lençol freático subterrâneo e ecossistemas de banhados, brejos, mangues, etc.

A qualidade ambiental dos riachos pode ser observada pela quantidade de microhabitats disponíveis, diversidade de espécies, presença de espécies indicadoras de qualidade ambiental e estrutura trófica do ecossistema em questão. Os ecossistemas aquáticos degradados perdem biodiversidade e espécies sensíveis a qualidade de habitat podem desaparecer, enquanto as mais tolerantes comportam-se como oportunistas (CAVALHEIRO; FERREIRA, 2009). Consequentemente ocorre à homogeneização das assembléias e espécies generalistas passam a ser dominantes (FELIPE; SÚAREZ, 2010).

A ictiofauna dos rios e riachos configura um grupo importante nos estudos de integridade ecológica destes habitats por ocuparem variadas dimensões espaciais e temporais dos nichos e das teias tróficas (TEIXEIRA et al., 2005). Os filtros ambientais, a complexidade de habitat e a disponibilidade de recursos estão entre as características dos riachos que influenciam os padrões de composição e diversidade da ictiofauna (FELIPE; SÚAREZ, 2010). Algumas espécies de peixes altamente dependentes da qualidade de habitat por apresentarem restrições quanto ao ciclo de 
CAVALHEIRO \& NISHIJIMA, v(5), n5, p. 658 - 669, 2012.

\section{Revista Eletrônica em Gestão, Educação e Tecnologia Ambiental REGET/UFSM (e-ISSN: 2236-1170)}

vida referente aos locais de desova, alimentação e fuga de predadores são consideradas indicadoras de integridade ambiental (TEIXEIRA et al., 2005).

Os autores Souza \& Santos (2006) em uma análise socioambiental do Riacho do Meio (Imperatriz, Maranhão, Brasil) constataram que as doenças mais comuns junto à população ribeirinha são febre amarela, febre tifóide, dengue e diarréia, conseqüentes da proliferação de transmissores dentro do riacho. Entre as principais doenças hídricas provocadas por agentes biológicos patológicos presentes em águas contaminadas destacam-se: cólera, tifo, paratifo, amebíase, hepatite, esquistossomose e doenças de pele (SILVA, 1993). Segundo os autores, a contaminação humana pode ocorrer através da ingestão da água contaminada, contato com a pele e mucosas ou na preparação dos alimentos.

Nos países em desenvolvimento estima-se a perda de até um décimo do tempo produtivo de cada pessoa devido a problemas de saúde relacionados às águas contaminadas, além destas serem responsáveis por $80 \%$ das doenças da população e um terço dos óbitos (MORAES; JORDÃO, 2002).

A incompetência na gestão adequada de rios e riachos, para Musetti (2006), muitas vezes, é mascarada pelo poder público com obras desnecessárias, custosas e impróprias como impermeabilização do solo e canalização de rios e riachos como soluções rápidas para inundações, mau cheiro e desbarrancamentos. A canalização de cursos d'água em áreas urbanas infere na vazão e equilíbrio do sistema com um todo podendo provocar inundação em áreas adjacentes ou não canalizadas ao longo dos riachos (SILVA, 2003).

Os residentes das proximidades de cursos d'água além de possíveis problemas com inundações e poluição desenvolvem, muitas vezes, sentimentos de admiração, curiosidade e até mesmo carinho pelos rios, riachos, lagos e igarapés, explicitados em canções, poesias, pinturas, lendas, fotografias. Não são poucas as letras sobre o magnífico Guaíba de Porto Alegre ou o imponente rio Uruguai na divisa do Rio Grande do Sul, estado que leva no nome a menção à importância das águas. Assim, estas questões merecem atenção quando se elaboram projetos de recuperação de corpos hídricos degradados. Nas palavras de Musetti (2006, p. 59)

Não podemos proteger um córrego ou um rio, urbano ou não, por ser um aglomerado de átomos de hidrogênio e oxigênio (...) a consciência humana faz do tempo de sua experiência concreta uma realidade ímpar que transforma um rio (ou córrego, riacho etc.) num bem valioso (...) que atrai, congrega, fascina e enfeitiça tribos, povos e nações, ao longo de todo seu curso, de toda sua margem.

A Educação Ambiental contextualizada, portanto, é essencial aos projetos de restauração dos riachos degradados por enfocar ações socioambientais e não somente obras de infraestrutura. $\mathrm{O}$ estudo sociocultural e ações preservacionistas ou mitigatórias adequadas à realidade de cada comunidade, são possíveis através da Educação Ambiental quando estas ações são planejadas em conjunto com a população. Deste modo, surge a necessidade de abordar na escola a questão dos riachos degradados e trabalhar com os estudantes a importância de desenvolver uma postura consciente de preservação dos recursos hídricos.

O objetivo geral deste artigo consiste em analisar sob a ótica da Educação Ambiental na escola a problemática dos riachos degradados. São objetivos específicos: relacionar a proposta metodológica das Situações de Estudo à Educação Ambiental; refletir sobre a preservação dos riachos na perspectiva da Educação Ambiental na escola. 
CAVALHEIRO \& NISHIJIMA, v(5), n5, p. 658 - 669, 2012.

Revista Eletrônica em Gestão, Educação e Tecnologia Ambiental

REGET/UFSM (e-ISSN: 2236-1170)

\section{METODOLOGIA}

O presente estudo pode ser classificado como uma pesquisa descritiva utilizando o método de revisão bibliográfica. Segundo Ribeiro (2007) o principal objetivo de uma revisão bibliográfica é reunir ideias oriundas de diferentes fontes, visando construir uma nova teoria, ou uma nova forma de apresentação para um assunto já conhecido, sendo neste artigo, em específico, a investigação, análise e argumentação sobre o método das Situações de Estudo na abordagem da problemática dos riachos degradados sob a perspectiva da Educação Ambiental. Para Berto \& Nakano (1998) as pesquisas classificadas como revisão bibliográficas são produtos de reflexões críticas sobre um fenômeno ou questão observada na literatura, compilando-se, contrapondo argumentos e teorias de diferentes autores sobre um determinado tema.

Assim, a técnica metodológica empregada nesta pesquisa utilizada para obtenção das informações sistematizadas, sintetizadas e reelaboradas a partir de reflexões críticas dos autores é a pesquisa bibliográfica que permite construir (ou reconstruir) ideias criando um arcabouço teórico capaz de sustentar ou subsidiar as questões sobre Educação Ambiental.

\section{RESULTADOS E DISCUSSÃO}

\section{A preservação dos riachos, a Educação Ambiental e a escola.}

Os riachos são recursos naturais que precisam ser preservados. Segundo Blank et al. (2008), a escassez hídrica no Brasil deriva principalmente da degradação da qualidade dos mananciais de água disponíveis, em virtude de urbanização, industrialização, expansão agrícola e aumento exagerado da demanda deste recurso nos locais mais populosos.

A problemática dos riachos degradados trata-se de uma questão de cidadania que deve permear a vivência escolar por meio da Educação Ambiental contextualizada. Segundo Moraes \& Jordão (2002, p. 374):

As gerações atuais precisam de uma nova cultura em relação ao uso da água, pois, além da garantia de seu próprio bem-estar e sobrevivência, devem cultivar a preocupação com as próximas gerações e com a natureza, as quais, por certo, também têm direito a esse legado.

A Educação Ambiental contextualizada requer, além do estudo da realidade dos sujeitos envolvidos, o estudo e o entendimento do que é a Educação Ambiental e das possibilidades que emanam dela. Segundo a lei no 9.795, de 27 de abril de 1999, Art. 1ํ, entende-se

por educação ambiental os processos por meio dos quais o indivíduo e a coletividade constroem valores sociais, conhecimentos, habilidades, atitudes e competências voltadas para a conservação do meio ambiente, bem de uso comum do povo, essencial à sadia qualidade de vida e sua sustentabilidade (BRASIL, 2008, p.199).

Ideais de valores e atitudes que permeiem a relação homem e natureza são expressos na Educação Ambiental, bem como a valorização e preservação do meio ambiente, estando incluso tanto os recursos naturais nele disponíveis quanto a sociedade humana. Assim, a Educação Ambiental é "ideológica no sentido político, portanto, não é neutra, nem descontextualizada, nem acrítica" (HIGUCHI; AZEVEDO, 2004, p.67). A Educação Ambiental aborda, então, problemáticas globais e locais, com discussões sobre a política ambiental mundial, como o patrimônio hídrico de 
CAVALHEIRO \& NISHIJIMA, v(5), n5, p. 658 - 669, 2012.

\section{Revista Eletrônica em Gestão, Educação e Tecnologia Ambiental REGET/UFSM (e-ISSN: 2236-1170)}

um país num quadro internacional de relativa escassez de água, ou as necessidades de uma comunidade específica, com determinados interesses, como por exemplo, a preservação de um riacho pela população ribeirinha. Assim, as problemáticas globais podem refletir na localidade e vice-versa sendo que essa dinâmica precisa ser objeto de estudo da Educação Ambiental e a escola pode ser o espaço desta discussão.

$\mathrm{Na}$ perspectiva de Armond et al. (2008, p. 08) "a escola, em conjunto com seus profissionais, principalmente os professores, deverá contribuir significativamente para a propagação de referenciais educacionais de preservação ambiental" e, por esta razão, pesquisar como a questão dos riachos degradados pode ser trabalhada na escola por meio da Educação Ambiental, torna-se tão relevante.

A Educação Ambiental na escola é fundamental na formação de uma consciência ambiental por configurar o espaço onde o aluno dá sequência ao processo de socialização iniciado em casa, com seus familiares (NARCIZO, 2009) e possibilita uma sensibilização dos estudantes e conseqüente mudança de mentalidade e atitudes frente à própria sociedade, ao ambiente e aos recursos naturais (REZENDE et al., 2009).

A relação homem e natureza está associada, neste contexto, às definições de meio ambiente a serem exploradas como objeto de estudo da Educação Ambiental na escola. Estas definições e conceitos são dependentes das vivências sociais dos estudantes, refletindo, em algumas circunstâncias, o entendimento da comunidade em que estes sujeitos estão inseridos. Isso porque, a apropriação/reprodução da opinião das pessoas com as quais se convive, sobre determinado assunto, é passível de acontecer.

A sociedade, portanto, entendendo o meio ambiente por um paradigma exclusivamente antropocêntrico, provoca crises nas relações homem e natureza, como ocorre na perspectiva moderna (CENCl et al., 2006), e atitudes de preservação do meio perdem espaço. É imprescindível, deste modo, ao estudar riachos na Educação Ambiental, trabalhar os conceitos e perspectivas dos estudantes em relação ao ambiente. Entre as crises na relação homem versus natureza encontrase a preservação dos cursos d'água versus ocupação/benefício humano.

A equivocada visão utilitarista da humanidade em relação à natureza define os recursos naturais, como os riachos, como bens a serem apropriados para o benefício de um indivíduo/corporação/país e assim a natureza tem "uma utilidade para o homem, para o desenvolvimento econômico, sendo a ela atribuído um valor de mercado, pela sua capacidade de gerar produtos de exploração mercadológica" (CENCl et al., 2006, p. 04).

A Educação Ambiental, por outro lado, definindo o meio ambiente por uma visão biocêntrica, permite aos estudantes ressignificar as relações homem versus natureza e entenderse como sujeitos integrantes do meio em uma relação homem e natureza que precisa buscar o equilíbrio socioambiental e analisar os riachos, não como produtos a serem explorados, mas como elementos essenciais a sadia qualidade de vida de todas as espécies. Assim, trabalhar a Educação Ambiental na escola exige o entendimento de como é a relação da sociedade escolar com a natureza, definindo-se sociedade escolar os estudantes, professores, pais, etc.

A Educação Ambiental é um elemento de inclusão social (COMIS et al., 2005) e na escola precisa compreender os alunos como constituintes de uma comunidade escolar que extrapola as paredes de concreto da sala de aula. Então, as ações de Educação Ambiental na escola que propiciam a proteção do meio ambiente, incluindo-se os riachos como recursos naturais, são consideradas exercício de cidadania. Segundo Morin (2003, p. 65), "a educação deve contribuir para a auto-formação da pessoa (ensinar a assumir a condição humana, ensinar a viver) e ensinar como se tornar cidadão" e o estudante é visto como sujeito crítico, politizado, capaz de efetuar 
CAVALHEIRO \& NISHIJIMA, v(5), n5, p. 658 - 669, 2012.

\section{Revista Eletrônica em Gestão, Educação e Tecnologia Ambiental}

REGET/UFSM (e-ISSN: 2236-1170)

uma leitura holística do mundo e adotar uma postura ética em prol do desenvolvimento sustentável. Nas palavras de Zuquim et al. (2010, p.01)

a educação ambiental assume cada vez mais uma função transformadora, na qual a coresponsabilização dos indivíduos torna-se um objetivo essencial para promover um novo modelo de desenvolvimento, chamado por muitos de desenvolvimento sustentável.

O desenvolvimento sustentável permeia a valorização da diversidade étnica e cultural da espécie humana e prioriza o manejo produtivo da biodiversidade, de forma que questionar a problemática ambiental pela sustentabilidade deve transpor as barreiras divisórias estabelecidas entre o social e o natural, observando-se que estes sistemas estão dialeticamente imbricados e possuem autonomias e interdependências simultâneas (CENCl et al., 2006). Então, a Educação Ambiental é um meio de trabalhar a importância da sociedade se desenvolver de forma sustentável visando à preservação da integridade dos ecossistemas de riachos e sua biodiversidade por meio de relações dialógicas. O desenvolvimento sustentável

é um potencial para o desenvolvimento alternativo com base em novos modos de produção e estilos de vida, alicerçados pelas condições e potencialidades ecológicas de cada região, assim como na diversidade étnica e na autonomia das populações para a gestão democrática dos seus recursos, ou seja, dentro de uma perspectiva de desenvolvimento descentralizado e autóctone (CENCl et al., 2006 p.08).

As práticas de preservação ambiental, portanto, não resumem o desenvolvimento sustentável e pensá-lo segundo Cenci \& Kässmayer (2008, p. 03) é primeiramente "delinear os contornos da própria sociedade na qual hoje se vive" e compreender suas características já que o paradigma ecológico vigente "possui nesta própria sociedade as suas origens e fundamentos". A compreensão da sociedade e do modelo de desenvolvimento vigente pode ocorrer na escola quando o trabalho da Educação Ambiental extrapola as ideias preservacionistas e engloba as questões sociais através das relações dialógicas.

O diálogo é a base à construção do conhecimento, seja sobre desenvolvimento sustentável, preservação da natureza ou valorização da qualidade de vida humana. Barchi (2009, p. 76) escreve que no contexto de uma Educação Ambiental libertária

o que interessa são as conexões entre os diversos saberes, identificar as inúmeras representações sociais, criar diálogos entre elas e, a partir daí, manter a possibilidade delas estarem sempre em construção através da dialogicidade, resistindo à concepções totalizantes a respeito dos mais diversos temas da Educação Ambiental.

Uma argumentação adequada e bem fundamentada leva a questionamentos que são capazes de mudar/formar opiniões, e capazes, sobretudo, de fazer os estudantes pensarem sobre a necessidade de adotar uma postura de preservação. É possível entender a complexidade dos ecossistemas de riachos e a necessidade de preservação sem dialogar sobre eles? Sem trocar opiniões? Sem buscar o diálogo embasado em leituras da realidade ambiental de uma região, ou argumentar sobre aspectos de diversidade biológica, cultural da comunidade ribeirinha, recursos hídricos, escassez de água, entre outros? É possível entender a urgência da necessidade de conscientizar-se sobre a problemática dos riachos degradados sem dialogar? O diálogo é uma arte necessária à expressão do conhecimento para possibilitar sua ressignificação em novos níveis e contextos. Nas palavras de Freire \& Schor (1986, p. 123), 
CAVALHEIRO \& NISHIJIMA, v(5), n5, p. 658 - 669, 2012.

\begin{abstract}
o diálogo é o momento em que os humanos se encontram para refletir sobre sua realidade tal como a fazem e re-fazem (...) na medida em que somos seres comunicativos, que nos comunicamos uns com os outros enquanto nos tornamos mais capazes de transformar nossa realidade, somos capazes de saber que sabemos, que é algo mais do que só saber (...). Através do diálogo, refletindo juntos sobre o que sabemos e não sabemos, podemos, a seguir, atuar criticamente para transformar a realidade.
\end{abstract}

Os educadores ambientais, neste sentido, se efetivamente propõe-se a "educar", precisam proporcionar aos educandos a possibilidade de dialogar, pensar, analisar e entender o contexto socioambiental no qual estão inseridos. $\mathrm{O}$ ato de educar é "promover uma racionalidade dialógica, comunicativa, emancipatória" (GADOTTI, 2003, p. 117).

O sujeito que está educando-se ambientalmente se auto-avalia em termos de postura frente à natureza, analisa as condições do meio e reflete e questiona-se quanto às consequências de suas ações ao ambiente social e natural. Gadotti (2003, p. 17), define que educar ou educar-se "é saber 'ler' o mundo, conhecê-lo para transformá-lo e, ao transformá-lo, conhecê-lo".

O educando ambiental compreende, ao conhecer a realidade ambiental que preservar os riachos degradados é necessário, porque entende, quando estuda conceitos específicos de ecologia, saúde, sociologia e economia, as implicações da degradação ambiental à flora e à fauna, à qualidade de vida das populações ribeirinhas e ao retrocesso de desenvolvimento da localidade que escasseia irresponsavelmente seus recursos naturais. Entretanto, entender e ser capaz de analisar tais problemáticas não é sinônimo de ações preservacionistas. $O$ sujeito pode entender e não agir, mas a Educação Ambiental é capaz, embasada em conhecimento científico específico e com as práticas metodológicas adequadas, de sensibilizar o sujeito à ação.

A educação é, então, considerada um ato político, enquanto a aprendizagem é a significação e ressignificação dos conceitos mediada pelas interações do sujeito. No processo educativo é necessário, segundo Rodrigues \& Freixo (2009, p. 104), oportunizar o desenvolvimento da compreensão crítica que implica em atitudes críticas. Nas palavras dos autores,

A leitura crítica da realidade associada a certas práticas claramente políticas de mobilização e de organização constitui-se num instrumento que possibilita a formação de cidadãos comprometidos com a questão ambiental. Por este motivo, a escola é considerada um espaço de transformação da sociedade. Sua participação se concretiza na formação ambiental e ética das novas gerações, na perspectiva de transversalidade, situando-a no contexto das diversas influências que a sociedade exerce sobre o desenvolvimento das crianças.

A Educação Ambiental, assim, é um produto histórico que precisa ser trabalhada a partir da realidade do estudante, através de um diálogo permanente entre as áreas do conhecimento, priorizando-se uma visão holística do meio ambiente, não sem considerar as relações sociais.

O sujeito é indivíduo e ser social, ou seja, suas ações individuais refletem na sociedade e as ações sociais refletem nas experiências do indivíduo. Assim, trabalhar na Educação Ambiental as relações sociais e as peculiaridades de cada um como agente social possibilita ensinar a desenvolver-se humanamente ou abordar o desenvolvimento social sustentável. Nas palavras de Morin (2000, p. 17), "todo desenvolvimento verdadeiramente humano deve compreender o desenvolvimento conjunto das autonomias individuais, das participações comunitárias e da consciência de pertencer à espécie humana". 
CAVALHEIRO \& NISHIJIMA, v(5), n5, p. 658 - 669, 2012.

Revista Eletrônica em Gestão, Educação e Tecnologia Ambiental

REGET/UFSM (e-ISSN: 2236-1170)

A Educação Ambiental na escola, holística e transdisciplinar mediada nas Situações de Estudo.

A Educação Ambiental na escola precisa considerar o conhecimento prévio dos estudantes, ser transdisciplinar, contextualizada, dialógica, holística e complexa em vez de simplista e reducionista.

A abordagem da realidade ambiental de modo complexo, para Jacobi (2005, p. 243), perpassa a reflexão sobre as práticas existentes e as múltiplas possibilidades de uma "racionalidade e um espaço no qual se articulam natureza, técnica e cultura", entendendo-se a complexidade ambiental como "fundamental para identificar interpretações e generalizações feitas em nome do meio ambiente e da ecologia" (p. 246). A complexidade ambiental configura a reflexão crítica da problemática ambiental dos riachos degradados pelo diálogo das diferentes áreas e a possibilidade de desenvolver ações sociais contextualizadas, porque há participação social na elaboração e execução destas ações.

A Educação Ambiental sob a ótica da complexidade possui um enfoque humanista, holístico, democrático e participativo e prioriza a produção de novas práticas sociais, consistindose de ações integradas e permanentes. Assim, atitudes necessárias à proteção dos riachos degradados permeiam a Educação Ambiental e são embasadas em conhecimento específico, enquanto o diálogo e a troca de saberes na transdisciplinaridade são as estratégias para sensibilização dos indivíduos da importância da preservação ambiental. $O$ ato de sensibilizar é possibilitar conhecimento, mas, sobretudo, o questionamento do que se conhece e se tem como verdade.

As Situações de Estudo são estratégias de ensino que objetivam a integração das áreas do conhecimento na escola, distribuídas atualmente em componentes curriculares como ciências, matemática, física, português, artes, etc. e assim, podem ser um dos métodos às abordagens transdisciplinares e contextualizadas da Educação Ambiental. Uma Situação de Estudo caracterizase por considerar aspectos da vivência social dos estudantes e relacionar os conceitos científicos e tecnológicos trabalhados na escola com a realidade cotidiana do educando. Assim o trabalho sobre riachos degradados na ótica das Situações de Estudos precisa englobar as experiências pessoais e coletivas dos alunos em relação aos cursos d'água, mas também conceitos científicos como interações ecológicas intra e interespecíficas e com o próprio ecossistema de riacho. Maldaner \& Zanon (2001, p. 49) definem uma Situação de Estudo como

uma situação real (complexa, dinâmica, plural) e conseqüentemente rica, identificada nos contextos de vivência cotidiana dos alunos fora da escola, sobre o qual eles têm o que dizer e, no contexto da qual, eles sejam capazes de produzir novos saberes expressando significados para tais saberes e defendendo seus pontos de vista.

O desenvolvimento de uma Situação de Estudo, neste sentido, tem como premissa o conhecimento dos sujeitos do processo, os estudantes que irão participar das atividades propostas, os professores a contribuir com o projeto, o ambiente em que a experiência irá acontecer, sendo o segundo passo, os questionamentos sobre o que é relevante estudar, o porquê de trabalhar a problemática dos riachos degradados e como abordar os conceitos ecológicos permeados pela Educação Ambiental de forma significativa aos estudantes. Segundo GIPEC/UNIJUÍ (2003, p. 08) 
CAVALHEIRO \& NISHIJIMA, v(5), n5, p. 658 - 669, 2012.

Revista Eletrônica em Gestão, Educação e Tecnologia Ambiental

REGET/UFSM (e-ISSN: 2236-1170)

uma Situação de Estudo parte da vivência social dos alunos, visando facilitar a interação pedagógica necessária à construção da forma interdisciplinar de pensamento e a produção da aprendizagem significativa e contextualizada, rompendo, na prática, com a forma meramente disciplinar de organização de ensino.

Importa notar, segundo Faundez \& Freire (2002), que o mundo escolar, tal qual o mundo em si, é complexo e não se reduz a conceitos simples e fechados e por isso a Situação de Estudo abre possibilidades, como dinâmicas, saídas a campo, pesquisas, questionários para integrar os estudantes à comunidade escolar e desenvolver ações reflexivas sobre as problemáticas ambientais como os riachos degradados. A escola é feita por pessoas e estas não se enquadram em formas, ou são fáceis de apreender, uma vez que estão em eterno devir (MARCONDES, 2005). Assim, a flexibilidade das Situações de Estudos permite a abordagens da Educação Ambiental adequadas a cada realidade escolar, como por exemplo, estudar os impactos antrópicos da agricultura aos riachos em uma escola do meio rural ou os impactos dos efluentes de esgoto doméstico nos riachos das áreas urbanas em escolas da cidade.

A escola compreende um mundo peculiar de interação entre professores e estudantes que juntos constroem, aos poucos, conceitos e valores que podem ser levados para a vida e por isso relevante às abordagens de Educação Ambiental. Assim, aquela representa algo além de uma mera estrutura de concreto que a compõe. É o espaço de debate como na Ágora grega onde os pensadores produziam não só conhecimento técnico, mas cidadania. A escola é constituída das pessoas que buscam sempre conhecer o novo através do estudo que compreende pesquisa e dedicação. A escola é caracterizada pela ação das pessoas que participam e interagem com seus acontecimentos diários. Desta forma, a Situação de Estudos aplicada na escola não engessa o ensino, mas abre possibilidades de interações entre os sujeitos com base nas experiências sobre o objeto de estudo. Segundo Araújo (2004), a consciência dos sujeitos se constitui nas práticas socioambientais em que se encontram envolvidos, principalmente através de atividades concretas onde modificam a natureza e se modificam. As Situações de Estudo provocam a inquietação, necessária à sensibilização dos sujeitos, frente a uma problemática socioambiental.

\section{CONCLUSÕES}

A problemática dos riachos degradados analisada sob a ótica da Educação Ambiental na escola precisa ser abordada de forma transdisciplinar, considerando-se as vivências dos sujeitos e as relações socioambientais que eles estabelecem dentro e fora do ambiente escolar.

A proposta metodológica das Situações de Estudo pode ser relacionada à Educação Ambiental porque estas são estratégias de ensino que priorizam a aprendizagem holística, embasadas em experiências práticas e objetivam o diálogo entre as áreas do conhecimento na escola.

Os sujeitos participantes da Educação Ambiental na escola para entenderem os riachos degradados como recursos naturais a serem preservados e sensibilizarem-se desta necessidade, precisam envolver-se em atividades que proporcionem a reflexão crítica desta questão nos paradigmas de desenvolvimento local e global e assim adotar atitudes éticas em relação à natureza por suas próprias experiências.

A Educação Ambiental na escola, deste modo, é um instrumento dialógico para os estudantes conscientizarem-se, por suas vivências individuais e coletivas, da importância de preservação dos cursos d'água e da adoção de medidas mitigatórias aos impactos antrópicos negativos dos riachos brasileiros, enquanto as Situações de Estudo são uma metodologia 
CAVALHEIRO \& NISHIJIMA, v(5), n5, p. 658 - 669, 2012.

\section{Revista Eletrônica em Gestão, Educação e Tecnologia Ambiental}

REGET/UFSM (e-ISSN: 2236-1170)

adequada à sensibilização dos sujeitos porque trabalham com conhecimentos específicos aliados às questões sociais, contextualizando assim as propostas de ensino à realidade de cada escola.

\section{REFERÊNCIAS BIBLIOGRÁFICAS}

ARAÚJO, M. C. P. A Educação Ambiental e a formação da consciência dos sujeitos. In: ZAKRZEVSKI, S. B \& BARCELOS, V. (org.). Educação ambiental e compromisso social: pensamentos e ações. Erechim: Edifapes, 2004, p. 183-192.

ARMOND, N. B.; MORELLI, R. C. B.; SARAIVA, F.; BRANDÃO, R. \& AFONSO, A. Análises da dinâmica fluvial do rio Imboaçu - São Gonçalo - RJ - Brasil: reflexões sobre educação ambiental. In: Anais do II Simpósio de Recursos Hídricos do Sul-Sudeste. Rio de Janeiro - RJ: Associação Brasileira de Recursos Hídricos, de 12 a 17 de outubro de 2008.

BARCHI, R. Uma Educação Ambiental libertária. Revista Eletrônica do Mestrado em Educação Ambiental, v. 22, p. 69-85, 2009.

BERTO, R. M. V. S.; NAKANO, D. N. Metodologia da pesquisa e a Engenharia de Produção. In: Anais do XVIII Encontro Nacional de Engenharia de Produção - ENEGEP e IV International Congress of Industrial Engineering - ICIE, Niterói - RJ, UFF / ABEPRO, outubro de 1998.

BLANK, D. M. P.; HOMRICH, I. G. N. \& ASSIS, S. V. O gerenciamento dos recursos hídricos à luz do ecodesenvolvimento. Revista Eletrônica do Mestrado em Educação Ambiental, v. 20, p. 53-62, jan./jun. 2008.

BRASIL. MINISTÉRIO DO MEIO AMBIENTE. CONSULTORIA JURÍDICA. Legislação Ambiental Básica. Brasília: Ministério do Meio Ambiente, UNESCO, 350p. 2008.

CAVALHEIRO, L. W. \& FERREIRA, F. W. A ictiofauna do Arroio Campus, ljuí - RS: diversidade e recursos alimentares. Trabalho de Conclusão de Curso (Graduação em Ciências Biológicas) - Universidade Regional do Noroeste do Estado do Rio Grande do Sul, ljuí - RS, 2009.

CENCI, D. R. \& KÄSSMAYER, K. O Direito Ambiental na sociedade de risco e o conceito de justiça ambiental. In: Anais do IV Encontro da Associação Nacional de Pós-Graduação e Pesquisa em Ambiente e Sociedade (ANPPAS), Brasília - Distrito Federal, 4 a 6 de junho de 2008.

CENCI, D. R.; ROESLER, D. A. \& PROSSER, E. M. S. A crise da modernidade e a ética da vida na relação homem-natureza. In: Anais do 10 Seminário sobre Sustentabilidade, UNIFAE, Português, Centro Universitário Franciscano do Paraná, Curitiba - PR, Brasil, 2006.

COMIS, R.; VIEIRA, D. P.; PICAVÊA J. P.; QUEROL, E. \& QUEROL, M. V. M. Atividades de educação ambiental visando a melhoria da qualidade de vida da população do CEANE, em Uruguaiana, RS - prevenção das zoonoses e doenças transmitidas pela água não tratada. Revista Educação Ambiental em Ação, no 11, 2005.

ESTEVES, K. E. \& ARANHA, J. M. R. Ecologia trófica de peixes de riachos. In. CARAMASCHI, E. P.; MAZZONI, R. \& PERES-NETO, P. R. (Eds.). Ecologia de peixes de riachos. Oecologia Brasiliensis. PPGE-UFRJ, Rio de Janeiro, Brasil, v. 6, p. 157-182, 1999.

FAUNDEZ, A. \& FREIRE, P. Por uma pedagogia da pergunta. Rio de Janeiro: Paz e Terra, 2002. 
CAVALHEIRO \& NISHIJIMA, v(5), n5, p. 658 - 669, 2012.

\section{Revista Eletrônica em Gestão, Educação e Tecnologia Ambiental}

REGET/UFSM (e-ISSN: 2236-1170)

FELIPE, T. R. A. \& SÚAREZ, Y. R. Caracterização e influência dos fatores ambientais nas comunidades de peixes de riachos em duas microbacias urbanas, Alto Rio Paraná. Biota Neotropica, v. 10, n. 2, p. 143-151, 2010.

FREIRE, P. \& SHOR, I. Medo e ousadia: o cotidiano do professor. Rio de Janeiro: Paz e Terra, 1986.

GADOTTI, M. Saber aprender: um olhar sobre Paulo Freire e as perspectivas atuais da educação. In: LINHARES, C. \& TRINDADE, M. N. (Org.) Compartilhando o mundo com Paulo Freire. São Paulo: Cortez, 2003.

GIPEC/UNIJUÍ. Grupo Interdepartamental de Pesquisa sobre Educação em Ciências/ Universidade Regional do Noroeste do Estado do Rio Grande do Sul. Geração e gerenciamento dos resíduos sólidos provenientes das atividades humanas. Ijuí: UNIJUÍ, 2003.

HIGUCHI, M. I. G. \& AZEVEDO, G. C. Educação como processo na construção da cidadania ambiental. Revista Brasileira de Educação Ambiental, Brasília, v. 0, p. 63-70, 2004.

JACOBI, P. R. Educação ambiental: o desafio da construção de um pensamento crítico, complexo e reflexivo. Educação e Pesquisa, São Paulo, v. 31, n. 002, p. 233-250, 2005.

MALDANER, O. A. \& ZANON, L. B. Situação de estudo: uma organização do ensino que extrapola a formação disciplinar em ciências. Revista Espaço da Escola, UNIJUÍ, v, 11, n. 41, p. 45-60, 2001.

MARCONDES, D. Iniciação à história da filosofia: dos pré-socráticos a Wittgenstein. Rio de Janeiro: Jorge Zahar, 2005.

MORAES, D. S. L. \& JORDÃO, B. Q. Degradação de recursos hídricos e seus efeitos sobre a saúde humana. Revista Saúde Pública, v. 36, n. 3, p. 370-374, 2002.

MORIN, E. Os sete saberes necessários à educação do futuro. 2ed. São Paulo: Cortez; Brasília, DF: UNESCO, 2000.

MORIN, E. A cabeça bem feita: repensar a reforma, reformar o pensamento. 8a ed. Rio de Janeiro: Bertrand Brasil, 2003.

MUSETTI, R. A. Direito ambiental e ciências ambientais: integração responsável. Revista CEJ, Brasília, v. 35, p. 58-61, out./dez. 2006.

NARCIZO, K. R. S. Uma análise sobre a importância de trabalhar educação ambiental nas escolas. Revista Eletrônica do Mestrado em Educação Ambiental, v. 22, p. 86-94, 2009.

OLIVEIRA, D. C. \& BENNEMANN, S. T. Ictiofauna, recursos alimentares e relações com as interferências antrópicas em um riacho urbano no sul do Brasil. Biota Neotropica, v. 5, n. 1, p. 01-13, 2005.

REZENDE, C. N. V.; SILVA, S. L. C. \& SILVEIRA, T. C. Percepção ambiental e a prática docente nas escolas do meio rural do município de Itapetinga-BA. Revista Eletrônica do Mestrado em Educação Ambiental, v. 23, p. 493-514, 2009. 
CAVALHEIRO \& NISHIJIMA, v(5), n5, p. 658 - 669, 2012.

\section{Revista Eletrônica em Gestão, Educação e Tecnologia Ambiental}

REGET/UFSM (e-ISSN: 2236-1170)

RODRIGUES, I. O. F. \& FREIXO, A. A. Representações e práticas de educação ambiental em uma escola pública do município de Feira de Santana (BA): subsídios para a ambientalização do currículo escolar. Revista Brasileira de Educação Ambiental, Brasília, v. 4, p. 99-106, 2009.

RIBEIRO, J. L. D. Diretrizes para elaboração do Referencial Teórico e Organização de Textos Científicos. In: Anais do Seminário de Pesquisa II, Porto Alegre - RS, PPGEP / UFRGS, abril de 2007.

SANTOS, C. R. \& REIS, R. S. Avaliação do grau de poluição do riacho Cruz das Almas e suas implicações na balneabilidade da praia. In: Associação Brasileira de Engenharia Sanitária e Ambiental, trabalhos técnicos, Rio de Janeiro, ABES, 13p. Apresentação: Congresso Brasileiro de Engenharia Sanitária e Ambiental, 19a Feira Internacional de Tecnologias de Saneamento Ambiental, Foz do Iguaçu, PR, 14-19 set. 1997.

SILVA, F. J. A. Indisponibilidade de esgotamento sanitário e a poluição dos cursos de água. Revista Tecnologia, Fortaleza, v. 14, p. 09-16, dez. 1993.

SILVA, P. R. F. G. Indicadores ambientais do complexo hídrico Papicu/Maceió, Fortaleza-Ceará. $76 f$. Dissertação (Mestrado em Desenvolvimento e Meio Ambiente) - Universidade Federal do Ceará, Fortaleza, 2003.

SOUZA, D. V. \& SANTOS, L. C. A. Avaliação geoambiental de Imperatriz - MA: o caso do Riacho do Meio. In: Anais do VI Simpósio Nacional de Geomorfologia - Geomorfologia tropical e subtropical: processos, métodos e técnicas. Organização: União da Geomorfologia Brasileira e International Association of Geomorphologists. 2006.

TEIXEIRA, T. P.; PINTO, B. C. T.; TERRA, B. F.; ESTILIANO, E. O.; GARCIA, D. \& ARAÚJO, F. G. Diversidade das assembléias de peixes nas quatro unidades geográficas do rio Paraíba do Sul. Iheringia, Ser. Zool., Porto Alegre, v. 95, n. 4, p. 347-357, 2005.

TERRES, C. A. \& MÜLLER, M. M. L. Proposta de recuperação de área degradada às margens do Arroio do Engenho na Vila Concórdia, Guarapuava - PR. Revista Eletrônica Lato Sensu, UNICENTRO, v. 5, p. 2-17, 2008.

ZUQUIM, F. A.; FONSECA, A. R. \& CORGOZINHO, B. M. S. Educação Ambiental no ensino médio: conhecimentos, vivências e obstáculos. Revista Educação Ambiental em Ação. v. 33, 2010. 